\title{
Blended Learning
}

\author{
José Alberto Lencastre \\ Department of Curricular Studies and Educational Technology, Institute of Education, University of Minho, \\ Portugal \\ Clara Pereira Coutinho \\ Department of Curricular Studies and Educational Technology, Institute of Education, University of Minho, \\ Portugal
}

\section{INTRODUCTION}

In recent years, the training initiatives in blended learning increased enormously as a result of the different demands to integrate the Information and Communication Technologies (ICT) in educational systems. In HigherEducation, the blend approach is highly pursued because of its unique flexibility that allows the teacher to propose, in every situation, more advantageous training solutions for their students, contrary to mandatory classroom in Basic and Secondary schools. It seems that the blended learning approach, a concept often bordering others such as e-learning, distance education, online learning or open learning, allows you to get the best of both worlds, the face-to-face and the virtual, and be an alternative to the traditional classroom teaching models and to enhance the new forms of electronic learning environments that use only the virtual and the distance. The blended learning approach seems to have the advantages of some of the concepts described, as the flexibility to determine their own pace of learning, and removes the greater disadvantage which is the lack of human contact with colleagues and teacher.

\section{BACKGROUND}

With the introduction of ICT in teaching and learning, it becomes essential to reflect and clarify the terminology and concepts associated, in order to facilitate communication between the actors. This reflection serves both to clarify and justify the adoption of a particular concept in the field of ICT in education. In fact, there are different terminologies for very similar concepts, depending on being either more focused on technological aspects or closest to the pedagogical potential.
E-learning is a global concept for a set of diverse and opaque ways of learning using ICT. The concept of e-learning is thus sufficiently broad and far from being univocal. Rosenberg $(2001,2006)$ states that e-learning is a form of distance learning, but distance learning is not e-learning. For the author, the association between the two terms is usual but e-learning has come to accomplish what was not possible within the distance learning, for example: (1) the increased interaction teacher-student; (2) bilateral communication; (3) synchronous and asynchronous communication; (4) the inclusion of collaborative strategies; (5) mediated learning materials and strategies that encourage students to process information autonomously; (6) the systematic collection of data (through learning management systems [LMS]); and (7) updated and relevant information in real time. E-learning has many meanings, some with more emphasis on electronic component (such as the ability to obtain information through the Internet or to learn through multimedia resources), intrinsically associated with the Internet and the Web for authors such as Clark and Kwinn (2007), who claim that e-learning has to be accessible through Web-based technology tools. Others see e-learning in a more pedagogical learning dimension through communication, collaboration and cooperation in a virtual space. Masie $(1999,2006)$ combines the two aspects when he says that e-learning is the use of network technology to plan, deliver, select, manage and expand learning. What is obvious is that there is some uncertainty as to what exactly are the characteristics of the term e-learning. However, it is clear that all forms of e-learning - applications, programs, objects, sites, etc. - may provide a learning opportunity for individuals (Moore, Dickson-Deane, \& Galyen, 2011), values the communication and interaction dimensions

DOI: 10.4018/978-1-4666-5888-2.ch129 
in a previously unthinkable away by the inadequacy of existing technologies.

Generally, distance education refers to the scenario of providing access to learning for those who are geographically distant, thus not implying physical presence between the teacher and students. As regards the adulteration of concepts, distance education is the most widely used descriptor when referencing the distance learning. During the last two decades, the literature shows that many authors use inconsistent definitions of distance education and distance learning. Most times it seems to describe the effort to put the burden on learning (distance education) instead of training (distance learning). Some authors claim that distance education uses new media and associated experiments to produce distributed learning opportunities (Moore, Dickson-Deane, \& Galyen, 2011). Sometimes the term distance education encompasses the various forms of study that are not under the immediate supervision of the teacher in the classroom but benefit from the planning and guidance of a teacher (Garrison, 1985).

Online learning appears to be the most difficult term to define. Some authors use it as a synonym for e-learning, describing online learning as learning "fully" online (Oblinger \& Oblinger, 2005), while others identify online learning as a newer version of distance learning that improves access to educational opportunities for non-traditional students and/or unprivileged (Benson, 2002; Conrad, 2002). Lowenthal, Wilson, and Parrish (2009), simply refer to technology or to the context with which the technology is used. Most authors describe online learning as access to learning experiences through the use of any technology (Benson, 2002; Conrad, 2002) usually used in context of the classroom with resources available on the Internet. Other authors discuss the accessibility, connectivity, flexibility and ability to promote diversified interactions (Hiltz \& Turoff, 2005; Oblinger \& Oblinger, 2005). These authors, like many others, believe that there is a relationship between distance education and online learning, but seem insecure in their own narratives.

Open learning is a term often confused with distance education (Fraser \& Deane, 1997) or with distance learning (Rumble, 1989). According to this author, an open learning system is an approach to teaching and learning that puts the emphasis on the student's right to take decisions. The open learning system allows the student to start, stop, and move at his own pace and convenience. According to Paine
(1989, as cited in Fraser \& Deane, 1997, p. 25), “... open learning is both the process which focuses on access to educational opportunities and a philosophy which makes learning more client and student centred. It is learning which allows the learner to choose how to learn, when to learn, where to learn and what to learn as far as possible within the resource constraints of any education and training provision." This means that it is not only fairer access to education, allowing anyone the opportunity to start on the road to qualification via higher education, but also that the learning experience itself is more flexible. According to Fraser and Deane (1997, p. 25), flexibility can be provided in:

- The course/subject entry and exit times,

- The mode of learning,

- The mode of attendance,

- The resources made available for learning,

- The pace of learning,

- The interaction between learners,

- The support provided for learners, and

- The methods of assessment.

Thus, the ideal concept of open learning has focused on concern about a student-oriented system that cares more about learning than with the training. Student participation must be free of traditional academic requirements. Learning goals and evaluation should serve as a basis for decision-making. This philosophy of education aims to help people take responsibility for their own learning.

However, initially the system placed the students accessing learning content regardless of their individual profile, level of knowledge, learning styles and abilities. Nowadays it has been much discussed the possibility of the system being able to extract, interpret and analyse students objectives. Lewis (1990), speaks in freedom of learning, because the student should be able to select his goals and become involved in assessing compliance with the targets he choses: "It gives learners (...) greater choice not only the time and place of learning but also over what is learnt (content) and how (learning methods and style). Here open learning moves beyond issues of access to learning and into issues of control the curriculum itself, empowering clients with choices hitherto reserved to the learning professionals. Until recently, learners were given access to an existing curriculum, newly packaged; now learners 
7 more pages are available in the full version of this document, which may be purchased using the "Add to Cart" button on the product's webpage: www.igi-global.com/chapter/blended-learning/112536?camid=4v1

This title is available in InfoSci-Books, InfoSci-Computer Science, Science, Engineering, and Information Technology. Recommend this product to your librarian: www.igi-global.com/e-resources/library-recommendation/?id=1

\section{Related Content}

Attribute Reduction Using Bayesian Decision Theoretic Rough Set Models

Sharmistha Bhattacharya Halder and Kalyani Debnath (2014). International Journal of Rough Sets and Data Analysis (pp. 15-31).

www.igi-global.com/article/attribute-reduction-using-bayesian-decision-theoretic-rough-setmodels/111310?camid=4v1a

Reconfiguring Interaction Through the E-Marketplace: A Transaction Cost Theory Based Approach

Cecilia Rossignoli, Lapo Mola and Antonio Cordella (2009). Handbook of Research on Contemporary

Theoretical Models in Information Systems (pp. 311-324).

www.igi-global.com/chapter/reconfiguring-interaction-through-marketplace/35837?camid=4v1a

Analyzing the Use of Information Systems in Logistics Industry

Shaligram Pokharel (2009). Information Systems Research Methods, Epistemology, and Applications (pp. 225-246).

www.igi-global.com/chapter/analyzing-use-information-systems-logistics/23478?camid=4v1a

The WiMAX Network Solutions for Virtual Enterprises Business Network

Sebastian Marius Rosu, George Dragoi and Bujor Pavaloiu (2015). Encyclopedia of Information Science and Technology, Third Edition (pp. 6327-6338).

www.igi-global.com/chapter/the-wimax-network-solutions-for-virtual-enterprises-businessnetwork/113088?camid=4v1a 